\title{
Apreensão e construção do conhecimento científico: descompasso entre necessidades informacionais e pensamento crítico
}

\author{
Aida Varela Varela* \\ Igor Guimarães**
}

\begin{abstract}
Resumo Momento em que se focaliza a relação informação, conhecimento e desenvolvimento, faz-se necessária a discussão a respeito da situação de alunos do Ensino Médio e do Ensino Superior, sob a ótica da Information Literacy e da Information Literacy Education, com foco na apreensão e na construção do conhecimento científico no Ensino Superior, numa sociedade cognitiva e tecnológica que desafia o sujeito a incluir-se socialmente e a realizar-se individualmente. Os suportes de análise do tema deste artigo são os estudos e as pesquisas de instituições nacionais e internacionais sobre a proficiência em Letramento.
\end{abstract}

Palavras-chave information literacy education, competências e habilidades, letramento, conhecimento científico

\begin{abstract}
Given the contemporary centrality of the relation between information, knowledge and development, it is necessary to discuss the situation of High School and University students, from the point of view of Information Literacy and Information Literacy Education, focusing on the apprehension and construction of scientific knowledge, in the context of a cognitive and technolocal society that provokes the subject to include himself socially and to fulfill himself individually. The analytical bases of this article are studies and research of national and international institutions on proficiency in Literacy.
\end{abstract}

Keywords Information Literacy Education, competences and abilities, literacy, scientific Knowledge

\section{Introdução}

Assiste-se a uma crescente valorização dos pressupostos da chamada sociedade cognitiva, sociedade que estimula o sujeito a desenvolver, continuamente, conhecimentos, capacidades e atitudes, assumindo, como principal desafio, reduzir as diferenças entre aqueles que sabem aprender e os que não o sabem.

A informação e a comunicação constituem-se parâmetros fundamentais da contemporaneidade, associados às atuais tendências de expansão e valorização. Pode-se dizer que informação e

\footnotetext{
*Doutora em Ciência da Informação pela UnB e Professora do Instituto de Ciência da Informação da UFBA

** Estudante de Comunicação Social pela Faculdade da Cidade do Salvador e Analista Técnico do Centro de Treinamento Autorizado (ATC Bahia) / Fundação Luís Eduardo Magalhães (Flem).
} 
comunicação constituem-se entidades complexas, dinâmicas, que extrapolam um fluxo de informação.

A relação informação, comunicação e desenvolvimento é algo que vem ocupando a atenção de empresas, de grandes corporações e do mundo acadêmico, mobilizando os centros disseminadores de conhecimento e de cultura e a sociedade num sentido amplo. Não se trata de um fenômeno circunscrito aos países desenvolvidos, ao contrário, seu alcance é global.

No paradigma da comunicação defendido por Habermas (1991), que trata da racionalidade comunicativa que emerge de interações que se coordenam pela construção de entendimentos lingüísticos, o conhecimento aparece como uma realidade intersubjetiva, como um fenômeno social que resulta de uma "transação entre sujeitos", que buscam entender-se sobre o mundo.

Conhecimento é, então, entendimento de sujeitos a respeito de fatos (mundo objetivo), normas (mundo social) e vivências (mundo subjetivo), à luz de um reservatório de evidências, o "mundo da vida", isto é, de um reservatório de interpretações, organizado lingüística e culturalmente dado em tradições (OLIVEIRA, 1989).

Assim sendo, os processos pedagógicos de aprendizagem têm a finalidade de produzirem "novas competências nos campos da cultura, da vida em sociedade e da expressão das personalidades, libertas de qualquer amarra" (MARQUES, 1993 apud BOUFLEUER, 2001). Seu sentido, na verdade, depreende-se da tríplice tarefa que imputamos à educação: contribuir para a reprodução e renovação da cultura, para o estabelecimento e o reforço das solidariedades e para a formação de identidades pessoais.

A Universidade, na qualidade de centro autônomo de pesquisa e de criação do saber, é responsável pelo cumprimento da missão do ensino superior e pela difusão dos seus valores fundamentais. Para a consecução de suas finalidades educativas, a Universidade busca reforçar o seu papel de instituição social, procurando implementar ações que contribuam para a formação de cidadãos capazes de atuar, competentemente, no seu contexto social, com o compromisso de construir uma sociedade solidária e ética.

No Brasil, a Legislação da Educação Superior, referendada pela Lei de Diretrizes e Bases da Educação Nacional (LDB), n. ${ }^{0}$ 9.394/96, insere uma nova concepção curricular que confere maior autonomia didático-científica à Universidade, ratificada pelo Sistema Nacional de Avaliação que orienta a demanda, pressionando as instituições universitárias e, por conseqüência, os professores do Ensino Superior, a seguir os ditames internacionais.

Ao se observar o cenário a ser enfrentado pelos egressos da educação superior, percebe-se uma necessidade crescente de adaptabilidade às novas exigências de uma realidade em permanente mudança ao enfrentar novos tipos de problema que envolvem novos recursos tecnológicos, o que torna imprescindível o comunicar-se de forma eficaz, utilizando-se do raciocínio crítico, do processamento e reelaboração da informação recebida, gerando soluções originais, conscientizando-se de seus próprios processos cognitivos.

Segundo estudos e pesquisas apresentadas por instituições brasileiras e organizações mundiais, o ensino médio, no Brasil, pré-requisito para o Ensino Superior, apresenta resultados que levam a 
concluir que, no processo de letramento informacional, há fragilidades ainda na organização, disseminação da informação e no domínio das competências de transferência e transcendência para a construção do conhecimento, não havendo espaço, portanto, para o pensamento divergente.

Reconhecendo-se a força da informação e sua disseminação para a transformação do ser humano e do seu entorno, bem como o espaço que vem ganhando na sociedade o movimento information literacy e o information literacy education, este artigo propõe analisar a necessidade do letramento informacional para a apreensão e construção do conhecimento científico no Ensino Superior, num contexto de sociedade cognitiva e tecnológica que desafia o sujeito a incluir-se socialmente e a realizar-se individualmente. A ênfase recai sobre os estudos e pesquisas que avaliam as dificuldades encontradas pelos alunos do Ensino Médio e do Ensino Superior no domínio da leitura, especialmente em relação às competências de crítica e significação.

\section{Leitura: estudos e pesquisas}

Os interesses em realizar estudos de avaliação são diversos e constantes. No governo, esses estudos estão diretamente ligados à efetividade, eficiência, accountability e, mais amplamente, ao desempenho da Gestão Pública. Já na esfera da Universidade, a preocupação reside no estudo e debate de teorias educacionais e práticas pedagógicas que permeiam as formas de produção e construção do conhecimento na contemporaneidade. Entre os estudos avaliativos sobre proficiência em leitura, destacam-se o do Exame Nacional do Ensino Médio (ENEM), o dos Resultados do Sistema Nacional de Avaliação da Educação Básica (SAEB), o do Instituto Nacional de Pesquisas Educacionais Anísio Teixeira (INEP/MEC), o do Programa Internacional de Avaliação de Estudantes (PISA) e o dos Estudos e Pesquisas Acadêmicas em Educação e Leitura.

\section{Proposta e resultados de avaliação do ENEM / SAEB / INEP / MEC}

O ENEM, promovido pelo INEP, é realizado anualmente, desde 1998, com o objetivo de avaliar o desempenho do aluno ao término da escolaridade básica, para aferir o desenvolvimento de competências fundamentais para o exercício pleno da cidadania.

$\mathrm{Na}$ parte objetiva do exame, são propostas ao participante situações-problema originais devidamente contextualizadas na interdisciplinaridade das ciências, das artes e da filosofia, articuladas com o mundo em que se vive. Utilizam-se dados, gráficos, figuras, textos, referências artísticas, charges, algoritmos, desenhos, ou seja, todas as linguagens possíveis para veicular dados e informações. Quanto à outra parte do Exame - a redação -, tem sido elaborada de forma a possibilitar que o participante, a partir de subsídios oferecidos, realize uma reflexão escrita sobre um tema de ordem política, social, cultural ou científica.

O ENEM, quanto às exigências de competências em leitura, avalia o domínio de linguagens sem fronteiras de códigos lingüísticos, a interpretação de textos na dimensão de conjunturas, proposições e símbolos, a realização de operações que possibilitem ultrapassar uma dada 
situação ou problema chegando à sua conclusão, o recorte significativo de uma realidade às vezes complexa, a coordenação de pontos de vista em favor de uma meta, a análise de situações anteriores para definir ou redimensionar as seguintes.

Os resultados do ENEM, disseminados pelo MEC / SAEB, reforçam a necessidade de estudos e atitudes que otimizem o letramento informacional para a leitura, fortalecendo, assim, no Ensino Superior, o ato de ler. Apresenta, ainda, as diferenças associadas à escola pública e à escola particular, a última com índices mais altos que os da escola pública. Destacam-se as médias associadas à escolaridade do pai e da mãe e à faixa de renda familiar. As médias mais baixas, localizadas na escola pública, estão articuladas à ausência de escolaridade dos pais e às mais baixas faixas de renda familiar de um salário mínimo, inferindo-se que a desigualdade de letramento familiar e conseqüente falta de acesso à informação reflete-se no grau de proficiência cognitiva dos alunos.

Eis algumas considerações quanto ao domínio de competências selecionadas pelo Exame, tomando-se como referência os resultados de 2002, num universo de 1.318 .820 participantes (sendo 50,2\% da Região Sudeste, 26,6\% da Região Nordeste e 10,8\%, 5\% e 7,4\% das regiões Sul, Norte e Centro-Oeste, respectivamente):

Dominar a norma culta da Língua Portuguesa e fazer uso das linguagens matemática, artística e científica - $1,75 \%$ dos alunos situaram-se no grupo de desempenho considerado entre insuficiente e regular, $47,37 \%$ dos alunos situaram-se no grupo de desempenho considerado entre regular e bom e $50,88 \%$ dos alunos situaram-se no grupo de desempenho considerado entre bom e excelente.

Construir e aplicar conceitos das várias áreas do conhecimento para a compreensão de fenômenos naturais, de processos histórico-geográficos, da produção tecnológica e das manifestações artísticas - 3,51\% dos alunos situaram-se no grupo de desempenho considerado entre insuficiente e regular, 52,63\% dos alunos situaram-se no grupo de desempenho considerado entre regular e bom e $43,86 \%$ dos alunos situaram-se no grupo de desempenho considerado entre bom e excelente.

Selecionar, organizar, relacionar, interpretar dados e informações representados de diferentes formas, para tomar decisões e enfrentar situações-problema - 7,02\% dos alunos situaram-se no grupo de desempenho considerado entre insuficiente e regular, 59,65\% dos alunos situaram-se no grupo de desempenho considerado entre regular e bom e 33,33\% dos alunos situaram-se no grupo de desempenho considerado entre bom e excelente.

Relacionar informações, representadas em diferentes formas, e conhecimentos disponíveis em situações concretas, para construir argumentação consistente - 5,26\% dos alunos situaram-se no grupo de desempenho considerado entre insuficiente e regular, 54,39\% dos alunos situaramse no grupo de desempenho considerado entre regular e bom e 40,35\% dos alunos situaram-se no grupo de desempenho considerado entre bom e excelente.

Recorrer aos conhecimentos desenvolvidos na escola para elaboração de propostas de intervenção solidária na realidade, respeitando os valores humanos e considerando a diversidade sociocultural - $0,00 \%$ dos alunos situaram-se no grupo de desempenho considerado entre insuficiente e regular, $50,88 \%$ dos alunos situaram-se no grupo de desempenho considerado entre regular e bom e $49,12 \%$ dos alunos situaram-se no grupo de desempenho considerado entre bom e excelente. 
Diante dos resultados apresentados, percebe-se que, à medida que aumenta a complexidade das operações cognitivas, a exemplo do raciocínio hipotético-dedutivo e do inferencial para o estabelecimento de relações de causa e efeito em prol da organização da informação, objetividade e clareza nas organizações, há um decréscimo no percentual de desempenho bom e excelente.

Segundo as considerações pedagógicas sobre o ENEM 2001 e 2002 (BRASIL, 2001; BRASIL, 2002), a ausência do domínio de leitura compreensiva foi a causa principal de situar-se o desempenho dos participantes do ENEM entre insuficiente e regular, visto que a leitura compreensiva é um processo global difuso, intrinsecamente ligado às intenções do participante (leitor), dos professores autores das situações-problema, e ao contexto sociohistórico em que tanto o autor quanto o leitor estão imersos.

Compreender o texto das situações-problema do ENEM não é retirar quase que "fotograficamente" a resposta para o problema. O participante precisa construir um modelo mental da situação descrita, e isso requer uma série de habilidades anteriores: o reconhecimento de palavras, o entendimento das relações gramaticais e semânticas entre palavras e a integração das idéias e conceitos por meio de inferências.

As inferências intra-sentenciais exigem a associação das informações que se encontram no texto da situação-problema; as inferências pragmáticas necessitam de conhecimentos previamente construídos; e as inferências avaliativas exigem posicionamentos pessoais e envolvem valores. A leitura compreensiva é, portanto, um processo de integração e construção de significados.

Aliada à não assimilação de conteúdos básicos próprios, em sua maioria, ao ensino fundamental, a leitura superficial e fragmentada parece ter acarretado escolhas equivocadas de resposta na parte objetiva da prova e, na redação, resultou na elaboração de textos que, embora adequados ao tema proposto, apresentaram problemas na sua estruturação, em que pesem os poucos excelentes registros de desempenho nesta parte da prova (BRASIL, 2001; BRASIL, 2002).

No que se refere ao ENEM 2003, que integrou o universo de 22.000 escolas com oferta de $3^{\mathrm{a}}$ série do Ensino Médio, em todo o Brasil, não houve grandes diferenças do perfil socioeconômico de 2002. A faixa etária dos jovens que fizeram o exame em 2003, a sua grande maioria do sexo feminino, está situada no intervalo entre 17 e 21 anos (78,7\%). Do ponto de vista étnico, o ENEM 2003 também espelha a diversidade social brasileira, com 41,4\% de autodeclarados negros ou pardos e mulatos. Ao analisar as médias das competências dos candidatos na redação, verificou-se que o pior desempenho ocorreu na competência $\mathrm{V}$ : "elaborar proposta de intervenção para o problema abordado, demonstrando respeito aos direitos humanos".

Os documentos mais recentes sobre o ENEM, 2004 e 2005, registram que o referido exame ganhou, desde 2004, uma maior dimensão social. Com sua vinculação ao Programa Universidade para Todos (ProUni), do MEC, o ENEM possibilita a estudantes de escola pública bolsas para cursar o ensino superior. Previa-se em 2005, o exame chegaria a 727 municípios em 27 unidades da Federação, e que, além de promover a necessária identificação de competências e habilidades de seus participantes, ajudaria na justa distribuição de bolsas de estudo no ensino superior.

Ressalte-se que o que vem sendo registrado pelo ENEM é confirmado pelos relatórios do SAEB. A avaliação é realizada pelo INEP / MEC, em parceria com os Estados da Federação, por meio de amostra representativa de cada uma das séries investigadas $-4^{\mathrm{a}}$ e $8^{\mathrm{a}}$ séries do Ensino Fundamental e $3^{\text {a }}$ Série do Ensino Médio de escolas públicas e privadas.

Os testes são construídos com base numa matriz de referência, em que são explicitadas habilidades esperadas para cada um dos ciclos avaliados. Em língua portuguesa são investigadas 
as habilidades de leitura, abrangendo a capacidade do estudante para localizar informações explícitas e implícitas em um texto, de fazer inferências, identificar o tema, identificar a tese e relações de causa e consequiência, entre outras, sempre em textos de gêneros diversos e em graus de complexidade diferenciados.

Em 2003, participaram do SAEB cerca de 300 mil alunos, 17 mil professores e 6 mil diretores de 6.270 escolas das 27 unidades da federação. O objetivo do Sistema Nacional de Avaliação Básica é apoiar municípios, Estados e a União na formulação de políticas para a melhoria da qualidade do ensino, com o foco da aprendizagem de habilidades básicas e indispensáveis ao cidadão.

De acordo com o Relatório SAEB (2003), a avaliação permite ainda conhecer, detalhadamente, o dimensionamento das áreas do conhecimento pelos vários ciclos de estudo, traçar estratégias de ensino-aprendizagem e qualificar docentes para a melhoria da qualidade de ensino. Para tanto, as unidades de ensino precisam apropriar-se dos relatórios SAEB e adotar iniciativas de promoção do aprendizado para todos os alunos.

Como ilustração, no que se refere a resultados sobre a $3^{\mathrm{a}}$ série do Ensino Médio, o relatório SAEB registra que a média nacional de 2003 em Língua Portuguesa foi 266,7, o que significa que os alunos interpretam textos publicitários, com auxílio gráfico, correlacionando-o com enunciados verbais e informações em gráficos sobre boletins metereológicos divulgados em jornais. Ressalte-se que o indicador mínimo de proficiência para os concluintes do Ensino Médio é de 350 pontos. Observe-se, a seguir, o gráfico referente à Região Nordeste.

\section{Média de desempenho em Língua Portuguesa na $3^{\text {a }}$ série E.M.}

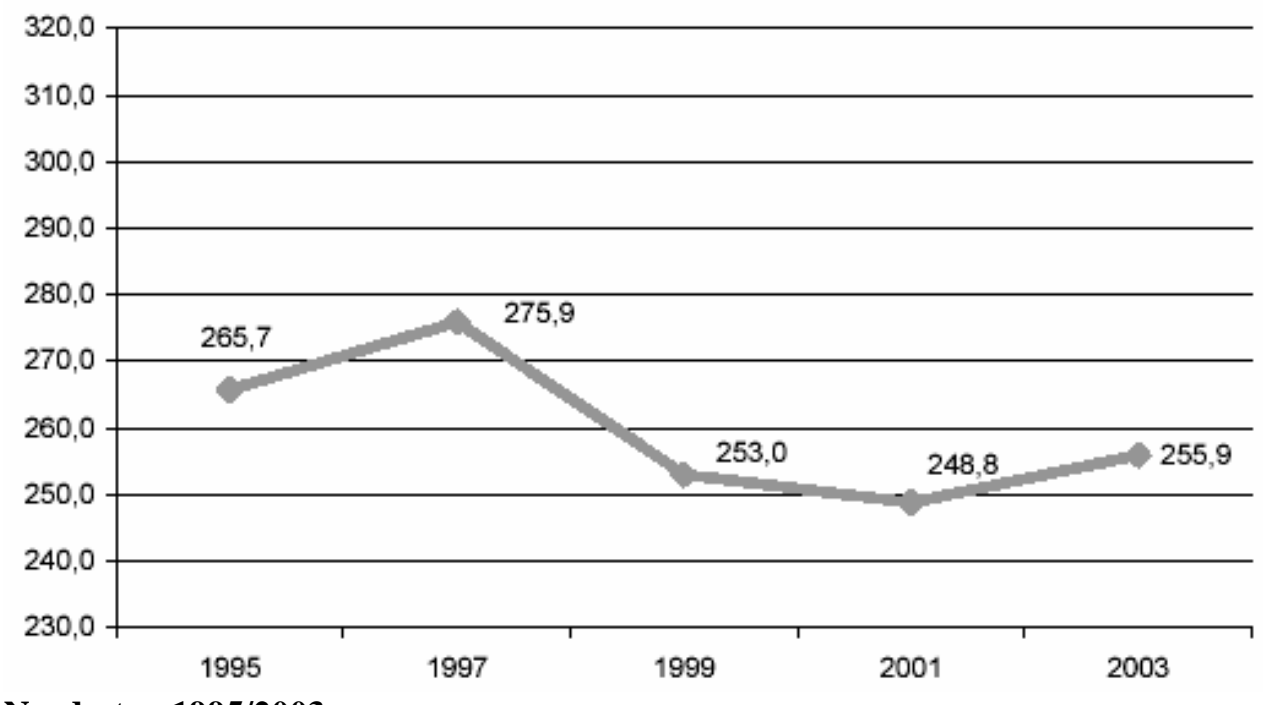

\section{Região Nordeste - 1995/2003}

Fonte: MEC/Inep/Saeb, 2003. 
Os resultados do SAEB também são analisados sob a ótica de construção de competências e desenvolvimento de habilidades de leitura de textos de gêneros variados, conforme a seguir:

\section{Percentual de estudantes nos estágios de construção de competências}

\section{Língua Portuguesa - 3ª Série E.M. - Brasil - Saeb 2001 e 2003}

\begin{tabular}{lcc|} 
Estágio & $\mathbf{2 0 0 1}$ & $\mathbf{2 0 0 3}$ \\
\hline Muito crítico & 4,9 & 3,9 \\
Crítico & 37,2 & 34,7 \\
Intermediário & 52,5 & 55,2 \\
Adequado & 5,3 & 3,2 \\
\hline Total & $\mathbf{1 0 0}$ & $\mathbf{1 0 0}$ \\
\hline
\end{tabular}

Legenda: Construção de competências e desenvolvimento de habilidades de leitura de textos de gêneros variados em cada um dos estágios (resumo).

\begin{tabular}{|l|l|}
\hline Muito Crítico & $\begin{array}{l}\text { Não são bons leitores. Não desenvolveram habilidades de leitura compatíveis com a 4a e 8a } \\
\text { séries. }\end{array}$ \\
\hline Crítico & $\begin{array}{l}\text { Ainda não são bons leitores. Apresentam algumas habilidades de leitura, mas aquém das } \\
\text { exigidas para a série (lêem apenas textos narrativos e informativos simples). }\end{array}$ \\
\hline Intermediário & $\begin{array}{l}\text { Desenvolveram algumas habilidades de leitura, porém insuficientes para o nível de letramento } \\
\text { da 3a Série (textos poéticos mais complexos, textos dissertativo-argumentativos de média } \\
\text { complexidade, texto de divulgação científica, jornalísticos e ficcionais; dominam alguns } \\
\text { recursos lingüístico-discursivos utilizados na construção de gêneros). Além das habilidades } \\
\text { descritas para os estágios anteriores, cabe destacar algumas habilidades pertinentes a este } \\
\text { estágio: depreendem relações de causa e conseqüência implícitas no texto; identificam efeitos } \\
\text { de sentido decorrentes do uso da pontuação (parênteses, reticências, exclamação); identificam } \\
\text { o tema a partir da articulação do título com as partes do texto; discriminam a hierarquia das } \\
\text { idéias de textos informativos mais complexos apontando a idéia principal entre as várias } \\
\text { opiniões emitidas de um determinado personagem. }\end{array}$ \\
\hline Adequado & $\begin{array}{l}\text { São leitores competentes. Demonstram habilidades de leitura compatíveis com as três séries do } \\
\text { Ensino Médio (textos argumentativos mais complexos, paródias, textos mais longos e } \\
\text { complexos, poemas mais complexos e cartuns e dominam recursos lingüístico-discursivos } \\
\text { utilizados na construção de gêneros). Em termos de habilidades, além das pertinentes aos } \\
\text { estágios anteriores, pode-se mencionar a identificação de informações explícitas no texto } \\
\text { informativo com base na relação entre partes do texto; identificam o tema de poemas mais } \\
\text { complexos com vocabulário pouco usual e distinguem, em dois textos, opiniões diferentes em } \\
\text { relação ao mesmo tema. }\end{array}$ \\
\hline
\end{tabular}

Fonte: MEC/Inep/Saeb, 2003. 
Comprova-se que, apesar do empenho do MEC em avaliar e disseminar informações, e, assim, estimular projetos de intervenção para incrementar o desenvolvimento de competências e habilidades de leitura na Educação Básica, um percentual significativo de estudantes ingressa na educação superior sem o devido desenvolvimento de funções e operações cognitivas para o ato de ler, não podendo o estudo universitário avançar no conhecimento específico necessário para a formação profissional.

\section{PISA - Programa Internacional de Avaliação de Estudantes}

O PISA - Programa Internacional de Avaliação de Estudantes - da OCDE - Organização para Cooperação e Desenvolvimento Econômico - foi criado para avaliar o grau de domínio em competências e habilidades dos jovens que estão prestes a concluir a escolaridade e enfrentar os desafios das sociedades atuais, em torno de três domínios: letramento em Matemática, letramento em Leitura e letramento em Ciências.

Os 30 países pertencentes à OCDE e mais de outros 20 países estão utilizando o PISA para obter uma perspectiva externa de seus próprios sistemas educacionais. Cada um deles pode sentir-se estimulado por determinados aspectos do desempenho dos demais para elevar suas próprias expectativas, e muitos já percorreram um longo caminho em direção à melhor compreensão do seu próprio desempenho, com base em padrões de qualidade universais. Os resultados das comparações internacionais consideram a questão sobre políticas que os países podem adotar para contribuir para que seus estudantes aprendam melhor, para que seus professores ensinem melhor e para que suas escolas se tornem mais eficazes.

Segundo estudiosos do PISA (KIRSCH et al., 2004) - Letramento em Leitura -, um fator importante para a compreensão em leitura é a quantidade de tempo que os estudantes gastam lendo. Se os estudantes lêem bem, tendem a ler mais e, conseqüentemente, adquirem mais conhecimentos em todos os domínios. Estudantes que têm hábitos deficientes de leitura freqüentemente acham que o material de leitura é difícil demais, portanto, desenvolvem uma atitude negativa em relação à leitura, acabam entrando em um círculo vicioso, uma vez que, por lerem menos, têm menos oportunidade de desenvolver estratégias de compreensão da leitura, e, dessa forma, ficam defasados em todas as disciplinas, já que a leitura é necessária para todas as áreas acadêmicas.

$\mathrm{Na}$ tentativa de simular situações autênticas de leitura, a avaliação de leitura do PISA (KIRSCH et al., 2004) mede os cinco seguintes aspectos associados à compreensão integral de um texto, seja este contínuo ou não-contínuo: construir uma compreensão geral ampla, recuperar informações, desenvolver uma interpretação, refletir sobre o conteúdo de um texto e avaliá-lo e refletir sobre a forma de um texto e avaliá-la. Embora haja uma relação entre os cinco aspectos todos eles podem, individualmente, exigir muitas das mesmas habilidades subjacentes -, o sucesso em um deles pode não ser dependente do sucesso em qualquer outro. Há quem acredite que estes aspectos estão no repertório do leitor em cada nível de desenvolvimento, ao invés de constituir uma hierarquia seqüencial ou um conjunto de habilidades.

Em relação aos níveis de proficiência no letramento em leitura, foi registrado que, em parte, as dificuldades são determinadas pela extensão, pela estrutura e pela complexidade do próprio 
texto. No entanto, notaram também que, na maioria das unidades de leitura, as questões ou instruções variam ao longo da escala de letramento em leitura. Isso significa que, embora a estrutura de um texto contribua para a dificuldade de um item, o que o leitor precisa fazer com o texto, definido pela questão ou instrução, afeta a dificuldade total da tarefa (KIRSCH et al., 2004).

Foram identificadas diversas variáveis que podem influenciar nas dificuldades de qualquer tarefa de letramento informacional para a leitura. $\mathrm{O}$ tipo de processo envolvido em recuperação de informações, desenvolvimento de interpretação ou reflexão sobre o que foi lido é um dos fatores relevantes. Os processos variam em complexidade e sofisticação, desde conexões simples entre itens de informação até categorização de idéias de acordo com determinados critérios, e avaliação crítica ou formulação de hipóteses sobre uma parte do texto. Além do tipo de processo evocado, a dificuldade de tarefas de recuperação de informações está associada ao número de informações a serem incluídas na resposta, ao número de critérios aos quais a informação obtida deve satisfazer, e ao fato de a informação recuperada precisar ou não ser seqüenciada de determinada forma. No caso de tarefas de interpretação e de reflexão, um fator importante que afeta a dificuldade é a quantidade de texto que precisa ser assimilada. Em itens que requerem reflexão por parte do leitor, a dificuldade é condicionada também pela familiaridade ou especificidade do conhecimento que precisa ser trazido de fora do texto. Em todos os aspectos da leitura, a dificuldade da tarefa depende de quão proeminente é a informação requerida, de quantas informações concorrentes são apresentadas, e do fato de as idéias ou as informações necessárias para a realização da tarefa estarem ou não explicitadas (KIRSCH et al., 2004).

\section{Estudos e pesquisas acadêmicas}

Profissionais de diferentes áreas de formação e de campos de atuação distintos têm-se preocupado com a questão da leitura, o que, por sua vez, leva-os a repensar a relação entre conhecimento e uso do código alfabético, uso e funções da palavra escrita nas interações sociais - processo de letramento. O interesse pela questão leva-os, também, a refletir sobre quais seriam as práticas de ensino-aprendizagem que propiciariam ao aluno oportunidades de, mais do que conhecer o código, incrementar a palavra escrita em sua vida, em diferentes situações de interação.

De acordo com Ferreira (2004), o crescimento na quantidade de dissertações de mestrado e de teses defendidas sobre leitura torna-se significativo nas duas últimas décadas, quando já se localizam 227 trabalhos, no período de 1980-1995, e um outro conjunto de 181 pesquisas em apenas cinco anos, de 1996 a 2000, totalizando 431 trabalhos.

Atualmente, o conceito de letramento desmistifica a divisão entre leitores e não-leitores, questiona as leituras legitimadas pela tradição cultural associada a determinados objetos, formas, lugares e modelos de leitor e traz em seu bojo as pesquisas que tematizam a leitura. O letramento tem sido, assim, no interior da produção acadêmica, um termo que ora substitui, ora amplia, ora se contrapõe ao conceito de leitura.

$\mathrm{O}$ foco de interesse dos pesquisadores se volta para descrever, entender e recuperar os elementos cognitivos, a dimensão interior desta experiência na relação/atividade do leitor com a informação e o conhecimento. Como se lê? Que habilidades ou competências são necessárias para apreender 
significados e para a leitura crítica? Quais são as dificuldades de leitura? Como processar o entendimento de textos dos mais simples para os mais complexos? (FERREIRA, 2004).

Um grupo de 104 dissertações de mestrado e teses de doutorado volta-se para instituições importantes na formação de leitores: a escola e a biblioteca. As pesquisas denunciam que a escola e a biblioteca têm falhado em sua função de formar leitores. Falhado pela ausência de atualização desses profissionais na área da leitura, pela falta de um acervo de livros compatível com as necessidades, interesses, expectativas de seus leitores e pela ausência de propostas pedagógicas mais eficientes, dinâmicas e atualizadas para as mudanças da sociedade (FERREIRA, 2001).

Em meados da década de 80 , nos relatos de propostas lúdico-pedagógicas e de críticas aos métodos tradicionais no ensino da leitura, um conjunto de dissertações e de teses constrói uma outra idéia da leitura, vinculada ao prazer e ao lazer, ancorada no conhecimento das preferências dos alunos, na facilidade de acesso aos livros, na substituição do imperativo da disciplina e da obrigatoriedade pela motivação, interesse e criatividade. É a leitura pelo prazer, o gosto de ler, a liberdade de escolher aquilo de que se gosta.

Ainda na década de 80, um grupo que reúne 48 trabalhos indaga: Que leitor é esse que passa pelas bibliotecas públicas e escolares, que se sujeita a diferentes propostas pedagógicas, que é examinado em grupos de controle em diferentes situações de leitura?

As primeiras pesquisas apontam para um leitor mapeado, identificado por sua classe social, econômica, escolar, faixa etária, fatores que interferem na produção dos interesses, das preferências, dos hábitos e gostos pela leitura. Os meninos preferem aventura, as meninas, romances; os alunos mais novos, iniciantes, livros com muitas figuras; os não familiarizados com a cultura escrita ou aqueles de classes mais populares preferem histórias adaptadas e modernizadas dos clássicos.

Outras pesquisas, já na década de 90, olham para esse leitor e buscam conhecê-lo pela sua história de leitura, pelas experiências vividas no interior da escola e fora dela. Relativiza-se, neste caso, a responsabilidade da escola e da biblioteca que oferecem alguns modos de ler e algumas habilidades. A leitura passa a ser entendida como uma prática social e não apenas escolarizada. As pesquisas buscavam imagens e representações construídas socialmente pelos sujeitos acerca da leitura, através de depoimentos, relatos, histórias de vida e de leitura, estudos de caso. Recentemente, alguns trabalhos voltam-se às práticas sociais de leitura ligadas a determinadas comunidades de leitores: leitura feminina de romances sentimentais de massa, como as leitoras da série Sabrina, leitores de Role Playing Games (RPG), leitores de assentamentos, leitores universitários.

Na discussão sobre o leitor, há um leitor muito especial, destacado nas pesquisas: o professor leitor, investigado em 35 trabalhos que trazem suas histórias de leitura, seus depoimentos de vida pessoal e profissional, buscando equacionar sua formação como leitor, conhecer suas práticas, modos de ver e de sentir a leitura, os livros. As pesquisas apontam para um professor marcado pelo desprestígio social da profissão, pelo seu exíguo salário, pelo seu tempo escasso, por não apresentar as mínimas condições de ser leitor.

Partindo de um modelo de leitor ideal (aquele que lê muito, sistemática e freqüentemente, obras de literatura normalmente clássicas e legitimadas pela academia, aquele que assina e lê jornais de grande circulação e revistas especializadas), os trabalhos denunciam a ausência de leitura por parte do professor. Quanto ao professor em formação, os pesquisadores mostram-se preocupados 
em equacionar os currículos dos cursos de graduação, bem como a inclusão de disciplinas que possam assegurar a produção de "novos" conhecimentos, ainda durante seu processo de formação inicial, capacitando esse formando para que ele possa contribuir com a importante função social da escola - formar leitores.

\section{Reflexões}

Que lugar é reservado ao leitor para o fortalecimento do letramento informacional para o desenvolvimento de habilidades de leitura compreensiva e crítica nos cursos universitários? Formam-se leitores ou, ao contrário, instala-se ou reforça-se o "desgosto" pela leitura?

O fato é que investigar a relação entre alfabetização e letramento, entre conhecimento do código e prática, implica a revisão e o redimensionamento de vários outros conceitos: o de ler e escrever, o de língua escrita e de língua falada, o de práticas orais e de práticas escriturais de produção de textos. Essa postura exige, também, obviamente, que se repense o que é ensinar/aprender uma língua e seus usos.

Que prática ou práticas pedagógicas desenvolvem habilidades para investigar e diagnosticar os problemas que afetam o usuário quanto à aquisição do conhecimento? Como objetivar a formação de um "gestor da informação" com atitude investigativa?

Como recém-egresso do Ensino Superior (um autor) e como docente (o outro autor) do Ensino Superior do Instituto de Ciência da Informação (ICI) da Universidade Federal da Bahia (UFBA), já passamos pelas dificuldades quanto à seleção de textos e quanto ao grau de complexidade cognitiva de leitura exigida por um curso de Graduação. Diante dessa situação, percebemos que, cada vez mais, há um distanciamento na apreensão do conhecimento científico, pois a informação nem sempre está acessível aos estudantes por conta da falta de desenvolvimento de competências e habilidades de leitura para buscar e usar a informação e, conseqüentemente, a não transformação da informação em conhecimento.

Desejamos, portanto, comprovar o que era divulgado pelos estudos e pesquisas que avaliam as dificuldades no domínio da leitura, principalmente, em relação às competências de crítica e significação. Para tanto, foi aplicado um questionário a 60 alunos ingressos no Ensino Superior de tres turmas de Graduação em Biblioteconomia e em Arquivologia, semestre 2005.2. Foi delineado o seguinte perfil: maioria do sexo feminino $(78,4 \%)$; estudantes de Biblioteconomia $(62,7 \%)$ e de Arquivologia (37,3\%); motivo da escolha do curso: oportunidade (47,0\%), gosto pela profissão $(21,6 \%)$ outros motivos $(31,4 \%)$; tipo de escola em que concluiu o Ensino Médio: escola pública $(82,4 \%)$; participantes do ENEM (39,2\%); escolaridade do pai: Ensino Médio completo $(33,3 \%), 1^{\mathrm{a}}$ a $4^{\mathrm{a}}$ série do Ensino Fundamental $(19,6 \%)$, Ensino Médio incompleto (19,6\%); escolaridade da mãe: $1^{\text {a }}$ a $4^{\text {a }}$ série do Ensino Fundamental $(29,4 \%)$, Ensino Médio completo $(27,6 \%), 5^{a}$ a $8^{a}$ série do Ensino Fundamental (21,5\%); dos respondentes, 96,1\% declararam que gostam de ler; a freqüência que o aluno dedica à leitura: quase todos os dias $(66,6 \%)$, uma ou duas vezes por semana $(23,5 \%)$; tempo que o aluno dedica à leitura diariamente: entre uma e duas horas $(49,0 \%)$, entre meia e uma hora $(37,3 \%)$; quanto ao que costuma ler: livro didático - sempre $(56,8 \%)$, às vezes $(41,2 \%)$; jornais - sempre $(60,8 \%)$, às vezes $(35,3 \%)$; revistas de informação - sempre $(64,7 \%)$, às vezes $(35,3 \%)$; revistas de humor às vezes $(58,5 \%)$, nunca $(41,2 \%)$; revistas científicas - sempre $(45,1 \%)$, às vezes $(39,2 \%)$, nunca $(15,7 \%)$; romances - sempre $(31,4 \%)$, às vezes $(52,9 \%)$, nunca $(15,7 \%)$; quanto a dificuldades de 
leitura, os alunos, mesmo registrando não ter dificuldade em analisar o texto, sintetizar o texto, detectar idéias principais do texto, relacionar o conteúdo do texto com outros conteúdos estudados e compreender diferentes códigos de linguagem existentes no texto (escrita, gráficos, ilustrações, figuras, tabelas etc), 56,9\% afirmaram ter dificuldade em organizar dados e informações para argumentar. Entre as sugestões de estratégias para os professores ajudarem os alunos a melhorar o grau de proficiência em leitura estão: inovar metodologias de orientação para leitura, a exemplo de oficinas de leitura e de elaboração de textos $(37,2 \%)$, discutir textos em grupo $(29,4 \%)$, selecionar textos mais interessantes $(23,5 \%)$, estimular a organização de grupos de leitura $(17,6 \%)$, intensificar atividades de interpretação de texto e debates $(15,7 \%)$.

O perfil da clientela caracterizou-se por estudantes que chegaram ao curso de biblioteconomia e de arquivologia por acaso, por oportunidade, oriundos do ensino médio de escola pública, com escolaridade dos pais focada no ensino médio, estudantes que declaram gostar de ler e não ter dificuldade de leitura; contudo, isso não está refletido nos dados coletados em relação à frequiência de leitura, no tempo dedicado à leitura, no que costumam ler, na dificuldade de leitura registrada - "organizar dados e informações para argumentar" - e nas sugestões apresentadas para melhorar o grau de proficiência em leitura.

Infere-se, portanto, que as turmas consultadas não cheguem, com facilidade, à leitura de textos científicos complexos, o que é testemunhado, cotidianamente, durante as aulas, em atividades de leitura, de apresentações orais e escritas, e, entre outros aspectos, não dominam a expressão oral e escrita da língua, exibindo dificuldades na construção de argumentos, em resumir e sintetizar, em detectar e resolver situações-problema, estabelecer relações, tudo isso aliado à falta de técnicas alternativas para estudar, além de demonstrar baixa estima quanto às próprias potencialidades e habilidades.

As evidências mostram a necessidade do desenvolvimento de esquemas intelectuais necessários à abstração e estratégias de aprendizagem que subsidiem o aluno em solucionar situaçõesproblema.

Nesse novo cenário, tem sido repensado o modo como vêm sendo trabalhadas a organização, a disseminação e a transcendência da informação nos vários segmentos educacionais. No ensino superior, é preciso formar sujeitos com autonomia intelectual, com paixão pela busca do conhecimento, com postura ética, comprometidos com os destinos da sociedade humana.

Boufleuer (2001) apresenta a seguinte problemática: os educadores constituem um dos grandes segmentos profissionais com maiores dificuldades para definir ou identificar os suportes básicos a partir dos quais entendem e justificam suas ações individuais e coletivas. Encontram-se os educadores frente à multiplicidade de saberes intervenientes em suas práticas, aliada à crise e à indefinição no tocante a um quadro teórico-conceitual de referências; encontram dificuldades para um adequado discernimento das situações com as quais se deparam. Para não transformarem suas práticas simplesmente arbitrárias, é mister que encontrem razões capazes de fundamentá-las, garantindo, com isso, a identidade e a coerência do exercício profissional.

Por outro lado, conforme registrado por Freitag (1993 apud BOUFLEUER, 2001), há o diagnóstico da sociedade contemporânea feita por Horckheimer, Adorno, Marcuse e outros: o homem do nosso tempo perdeu a capacidade de objetivar, criticamente, o mundo em que vive; o poder econômico impulsionado e legitimado pela ciência e pela técnica domina o processo social; a reflexividade crítica foi cerceada pelo amplo processo de ideologização, porque transformou o homem contemporâneo num ser econômico, unidimensional; o projeto iluminista, que previa a libertação de todas as escravidões, chegou a um impasse no momento em que o 
homem se tornou escravo das forças que ele mesmo imprimiu ao processo histórico; o homem perdeu o controle de sua razão e ela já não está a serviço da construção de sua felicidade.

Pelo exposto, o desafio que se coloca, neste início de século, e ainda diante do uso extensivo das tecnologias da informação e da viabilização de condições para que as pessoas compartilhem os significados que podem ser atribuídos às informações - a construção de conhecimento

significativo - é o de que as instituições responsáveis pela disseminação de conteúdos se transformem em comunidades dedicadas à construção coletiva de significados e passem de meros intermediários do processo de aquisição da informação a construtores do conhecimento. Para tanto, delineia-se uma mudança de paradigma, um modelo centrado no sujeito/usuário voltado para o aprendizado como processo contínuo de internalização de fundamentos conceituais, atitudinais, comportamentais e de habilidades necessárias à compreensão e interação permanente com o universo informacional e sua dinâmica - Information Literacy -, quando professores e bibliotecários integram-se em prol do fortalecimento da apreensão e da construção do conhecimento científico.

\section{Referências}

ABRAMOVAY, M.; CASTRO, M. Ensino médio: múltiplas vozes. Brasília: Unesco: MEC, 2003.

BOUFLEUER, J. P. Pedagogia da ação comunicativa: uma leitura de Habermas. 3. ed. Santa Rosa: Unijuí , 2001.

BRASIL. Ministério da Educação. Secretaria de Educação Média e Tecnológica. Instituto Nacional de Exames e Pesquisas Educacionais Anísio Teixeira. Exame Nacional do Ensino Médio. Documento básico. Brasília: MEC/INEP, 1998.

BRASIL. Ministério da Educação. Secretaria de Educação Média e Tecnológica. Parâmetros curriculares nacionais: ensino médio: bases legais. Brasília: MEC/INEP, 1999.

BRASIL. MINISTÉRIO DA EDUCAÇÃO. Secretaria de Educação Média e Tecnológica. Exame Nacional do Ensino Médio. Relatório pedagógico 2001. Brasília: MEC/INEP, 2001. Disponível em: http://www.inep.gov.br/download/enem/2001/relatorio_final/relatorio2001.pdf. Acesso em: jul. 2006.

BRASIL. Ministério da Educação. Secretaria de Educação Média e Tecnológica. Exame Nacional do Ensino Médio. Relatório pedagógico 2002. Brasília: MEC/INEP, 2002. Disponível em: http://www.inep.gov.br/download/enem/2002/relatorio_pedagogico_2002/rp2002_1.pdf Acesso em: jul. 2006

BRASIL. Ministério da Educação. Secretaria de Educação Média e Tecnológica. Exame Nacional do Ensino Médio. Relatório pedagógico 2003. Brasília: MEC/INEP, 2003.

BRASIL. Ministério da Educação. Secretaria de Educação Média e Tecnológica. Instituto Nacional de Exames e Pesquisas Educacionais Anísio Teixeira. Exame Nacional do Ensino Médio: Sumário Executo. Primeiros resultados. Brasília: MEC/INEP, 2003. 
BRASIL. Ministério da Educação. Secretaria de Educação Média e Tecnológica. Instituto Nacional de Exames e Pesquisas Educacionais Anísio Teixeira. Sistema Nacional de Avaliação da Educação Básica. Resultados do SAEB 2003: versão preliminar. Brasília: MEC/INEP, 2004.

BRASIL. Ministério da Educação. Secretaria de Educação Média e Tecnológica. Instituto Nacional de Exames e Pesquisas Educacionais Anísio Teixeira. Exame Nacional do Ensino Médio. Informativo Enem 2005. Brasília: MEC/INEP, 2005.

DEVLIN, K. Info-senso: como transformar a informação em conhecimento. Lisboa: Livros do Brasil, 2000.

DUDZIAK, E. A. A Information Literacy e o papel educacional das bibliotecas. Dissertação (Mestrado em Ciências da Comunicação) - Escola de Comunicações e Artes da Universidade de São Paulo, São Paulo, 2001.

ECO, U. From internet to Gutenberg: a lecture presented at the Italian Academy for Advanced Studies in America. Nov. 12, 1996. Disponível em: <http:// www.italynet. com/columbia/internet.htm>. Acesso em: 12 jun. 2001.

FERNANDES, G. C. O objeto de estudo da ciência da informação. Informare: Cadernos do Programa de Pós-graduação em Ciência da Informação, Rio de janeiro, v. 1, n. 1, p. 25-30, jan./jun. 1995.

FERREIRA, N.S. A. A pesquisa sobre leitura no Brasil, 1980-2000. Campinas: Komeid : Arte e Escrita, 2001.

Catálogo analítico de dissertações de mestrado e teses de doutorado: a pesquisa sobre leitura no Brasil, 1980-2000. Campinas: Unicamp, 2003.

Leitura como objeto de investigação. Revista da FAEEBA: educação e contemporaneidade, Salvador: Uneb, v. 13, n. 21, jan./jun. 2004.

HABERMAS, J. The Structural Transformation of the Public Sphere: An Inquiry into a Category of Bourgeois Society. Cambridge: MIT Press,1991.

KIRSCH et al. Letramento para mudar: avaliação do letramento em leitura: resultados do PISA 2000. São Paulo: Moderna, 2004.

KLEIMAN, A. Texto \& leitor: aspectos cognitivos da leitura. 6. ed. Campinas: Pontes, 1999.

LYMAN, L. Literacy education as Library community servive. Library Friends, [S.1.], v. 28, n. 2, p.193-217, fall 1979.

RODRIGUES, M.E.F., CAMPELLO, B S. (Org.). A (re)significação do processo de ensino/aprendizagem em biblioteconomia e ciência da informação. Niterói : Intertexto; Rio de Janeiro: Interciência, 2004.

VARELA, A V. Informação e autonomia: a mediação segundo Feuerstein.. Tese (Doutorado em Ciências da Informação) - Departamento de Ciência da Informação e Documentação, Universidade de Brasília, Brasília, 2003 